\title{
Short-Termism, Excessive Executive Compensation, and the Discounting Traits of Managers - by Using fMRI Experiment
}

\author{
Hidetoshi Yamaji ${ }^{1, *}$, Masatoshi Gotoh ${ }^{2}$, Yoshinori Yamakawa ${ }^{3}$ \\ ${ }^{1}$ Graduate School of Management, Kyoto University, Japan \\ ${ }^{2}$ Graduate School of Business Administration, Kobe University, Japan \\ ${ }^{3}$ NTT Data Institute of Management Consulting, Inc., Tokyo, Japan
}

Received January 7, 2020; Revised March 9, 2020; Accepted March 19, 2020

Copyright $\bigcirc 2020$ by authors, all rights reserved. Authors agree that this article remains permanently open access under the terms of the Creative Commons Attribution License 4.0 International License

\begin{abstract}
It can be said that short-termism and excessive executive compensation are drawing critical and negative attention in recent years, judging from famous politician's lecture and the passage of law forcing to publicly disclose the ratio of the compensation of the chief executive officer (CEO) to the median compensation of that company's employees. We assume that these management problems are sharpened by human instinctive discounting behavior. By brain experiment of discounting behavior (neuro-science method), we scientifically reveal that stimuli like globalization mobilize new brain parts (precuneus, IPL, TPJ), sharpen human discounting behavior and in turn sharpen the management problems. The research results show that human beings predict other people's discounting behavior more sharply than their own by additionally activating new parts of brain. This in turn will sharpen their discount behavior. This chain of discounting behavior and activation of new brain parts becomes prominent in the globalization of economies involving more strangers. In order to stop the sharpening of management problems, improvement policies counter to human instincts become necessary. Our research results are closely related to resolve some of the problems by using accounting institutions. For example, since the institutionalization of the quarterly report promotes the short-termism, its rectification is necessary. Also, in order to correct the distortion of corporate compensation structure, the SEC oversees the disclosure of remuneration for middle-ranking worker and is seeking full-fledged institutionalization. Implementation of these accounting policies are strongly supported by our research results.
\end{abstract}

Keywords Short-Termism, Excessive Executive Compensation, Discounting Behavior, fMRI Experiment

\section{Introduction}

In 2015, two major management issues that had been raised previously were once again the focus of debate in the United States. Those two issues were short-termism and excessive executive compensation. The first issue can be seen in a speech given by Hillary Clinton at New York University on July 24, 2015, in which she used the term "quarterly capitalism" as she criticized short-termism in management, whereby companies neglect to make investments to promote long-term growth and instead focus on the pursuit of short-term profits. In terms of the latter issue, in an effort to curb excessive executive compensation, under the Dodd-Frank Wall Street Reform and Consumer Protection Act, firms were obligated to publicly disclose the ratio of the compensation of the chief executive officer (CEO) to the median compensation of that company's employees, but in August 2015, the SEC slightly amended the regulations in terms of the specific way in which that was to be done, which was to be implemented from 2018.

In addition, there are many researchers who consider short-termism to be one of the factors that led to the collapse of Lehman Brothers that occurred in the United States in 2008 (Dallas, [2]). However, this type of executive stance on short-term investment valuation is not something that just started recently; Michael Porter [19] was pointing to this as one of the reasons for the lagging international competitiveness of the United States in the 1990s. Going back even further, if we look at the fact that this is exquisitely described in Chapter 12 of John Maynard Keynes' General Theory of Employment, Interest and Money [12], there is a strong possibility that it is an inherent characteristic of mankind.

It has also been pointed out in recent years that there is 
a tendency for executives to increase their own compensation while maintaining low compensation for middle management, with whom they are relatively close, and laborers, from whom they are increasingly alienated. This distribution trend has continued to be noted particularly in America. Meanwhile, in contrast to the United States, Japan's culture, particularly following World War II, operated on a model of equality and fairness that meant the pay gap between executives and middle management or laborers was not as conspicuous as in the United States. However, in recent years, that gap has been expanding even in Japan (Kubo, [13]).

Each of these two management issues is a major issue in and of itself and thus they are often discussed separately, but they can also be viewed as being interconnected. It has been noted that the average holding period for stocks in America has shrunk to about seven months. Seventy percent of all US stock trades are made by "hyper-speed" traders who conduct extremely short-term trades, which in some extreme cases may entail holding times of just seconds. In the globalized stock markets that look for short-term profit margins at the global level, executives also are evaluated based on whether or not they produce short-term profits. Executives who are forced to make efforts to produce fast-breaking, short-term profits can easily find their abilities drying up and, given the international competition among executives, this has led to a trend toward shorter tenures as well. Accordingly, they try to acquire as much personal compensation for themselves as possible during that short tenure. It is thought that this is the reason that executive compensation has become relatively and excessively large in contrast to that of middle management and laborers. Thus, these two issues appear to be mutually related ${ }^{1}$.

Is it possible to take a slightly different perspective on these two issues and consider them in a unified way? Judging from Keynes' indications, it can be inferred that the causes of short-termism are found in mankind's essential disposition, as he says, "Human nature desires quick results, there is a peculiar zest in making money quickly, and remoter gains are discounted by the average man at a very high rate" (1936, Chapter 12, section V, p.157 [12]).

Also, the thinking behind the Dodd-Frank Act's regulation on public disclosure of compensation - namely, the idea of seeing whether or not the executive compensation is excessive based on the mid-range value of the compensation framework for what executives pay their workers - considers how the ratio of compensation that executives pay to lower-level employees to the compensation executives pay themselves decreases as the person's position gets lower.

When you think about these two management issues in this way, you realize that there is a common underlying issue: Both short-termism and the executive compensation problem seem to come down to one common element, the specific characteristic of management's discounting behavior.

Let us examine human discounting behavior and these two management issues. From a temporal perspective, it has long been known that human beings have a tendency to discount value to be achieved in the future or, in terms of interpersonal relations, they tend to discount the value of those who are remote. But in recent research, it has been empirically confirmed that the discounting trend is not exponential discounting, but rather a hyperbolic discounting whereby the more recent future value is discounted the most. In other words, as shown in figure 1, those who are prone to hyperbolic discounting rather than exponential discounting had a behavioral pattern whereby they would apply a large discount rate in the short term and a small rate in the long term. For example, in terms of time, the biggest discount in value is between today and tomorrow, while after that the discounting rate gradually becomes smaller. Similarly, in terms of interpersonal discounting the value given to those closer at hand is greatly discounted. In other words, "The value in the near future and of people close by is greatly discounted" (fig. 2). 


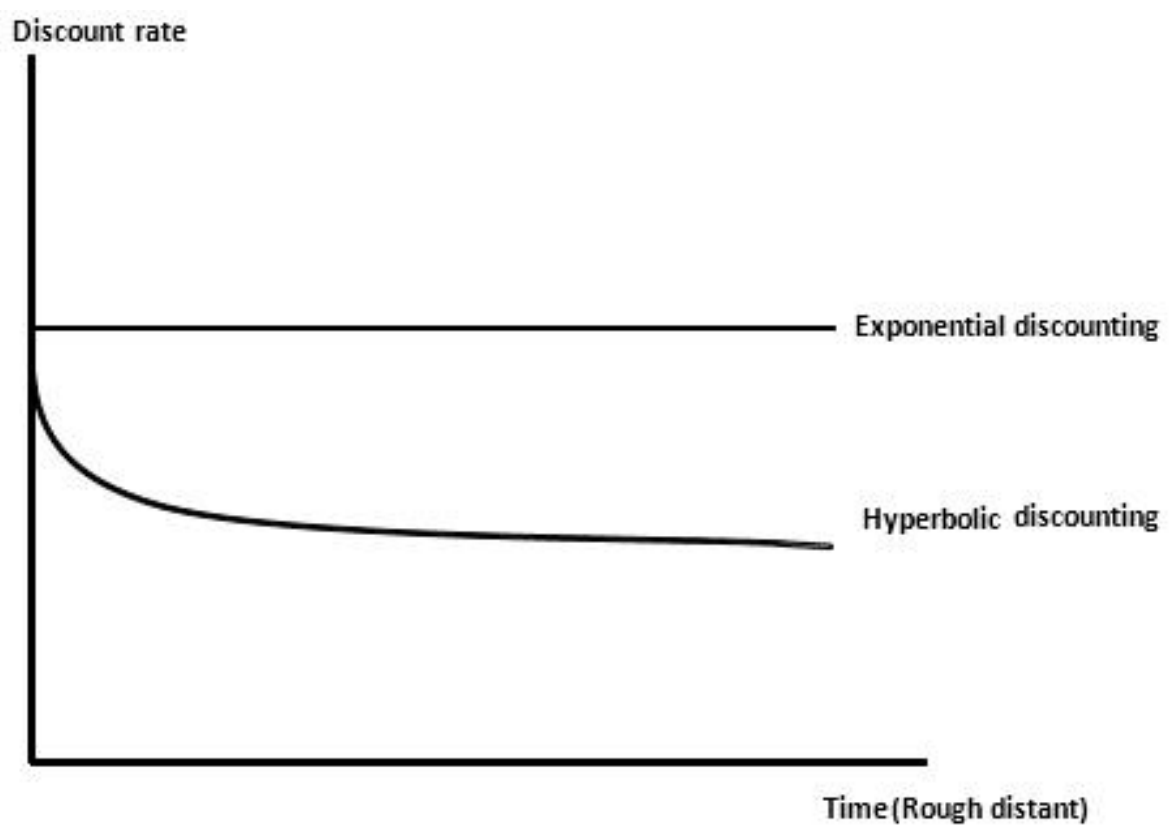

Figure 1. Exponential and hyperbolic discounting (discount rate)

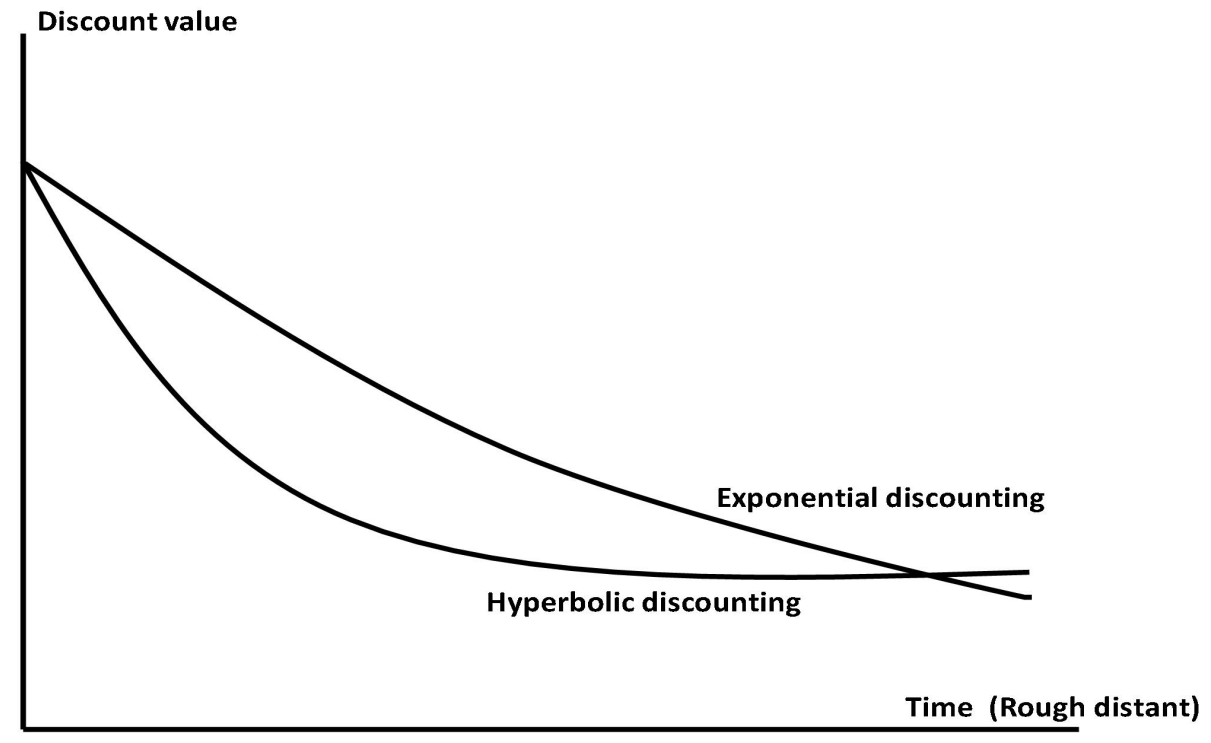

Figure 2. Exponential and hyperbolic discounting (discount value)

However, even if we assume that hyperbolic discounting is the inherent human discounting tendency, what is unique about the recent management issues is that manager discount rates have become even more radical, exceeding the general tendency, and that the focus on short-term performance and the attention that the relative increase of executive compensation has drawn are major issues characterizing modern management. Judging by the common economic environment that has been pointed to for these two issues, we agree with a direction of thinking that attributes the economic causes to the intensified business competition that has accompanied globalization, as is often said. In this paper, we are exploring what it is about the globalized environment that is influencing the discounting traits of managers and further intensifying the issues of short-termism and excessive executive compensation. As one hypothetical explanation, we would like to cite a brain experiment that indicates that in comparison to the discount rate applied by managers (human beings) in their own discounting behavior, when making assumptions about the discount rate of others, they tend to assume that it is larger than their own. The intensification of discounting behaviors can be thought to have arisen due to the fact that, while in the past there was competition among managers belonging to economic systems that followed similar patterns of behavior as one's 
own, globalization has thrust other people into those closed conditions and they are people whose actions cannot be understood according to the old patterns, making the environment more competitive and the future more difficult to predict. At that point, it can be inferred that the manager will predict the intruding outsider's discount rate for investment plans and executive compensation, determining that it is probably larger than his/her own and, being human, will revise and increase his/her own discount rate as his/her instincts kick in to protect him/herself not in the distant future, but today. Needless to say, raising the level of the discount rate means an intensification of short-termism and excessive executive compensation. The psychological behavior of managers based on this process of reasoning forms the core of this paper's analysis of the issue, and thus we have adopted brain experiment analysis that will allow us to substitute more objective data as we discuss this type of psychological behavior.

For the purposes of this essay, the human act of discounting the future value from a temporal perspective is referred to as "time discounting," while the act of discounting the value attributed to others in interpersonal relations is called "interpersonal discounting." Also, estimating one's own discount rate is called "individual discounting," while the act of estimating another person's discount rate rather than one's own, particularly in an expedient manner, is called "social discounting."

\section{Literature Survey}

In this section we overview the previous literature concerning time discounting and interpersonal discounting to help us to present the hypotheses in the next section.

\subsection{Overview of Time Discounting Research}

Normally, in economics there are two schools of thought: exponential discounting, which takes time rationality as the standard, and in which time discounting is premised upon time consistency, or in other words, the discount rate does not change over time; and hyperbolic discounting, which does not assume time rationality, and where the discount rate between two points in the immediate future is not the same as the discount rate between two points of an equal distance apart but in the more distant future, with the discount rate for the nearer future being larger. If we express hyperbolic discounting as an equation, it is

$$
\mathrm{v}=\mathrm{V} /(1+\mathrm{kD})
$$

where $\mathrm{V}$ : discounted value $\mathrm{V}$ : non-discounted value $\mathrm{D}$ : degree of time lag or closeness $k$ : individual parameters (in terms of time discounting, this indicates the individual's "degree of impatience," while in terms of interpersonal discounting, it represents the individual's "altruism"). ${ }^{2}$

First let us review the brain experiment literature related to time discounting. McClure et al. [15] indicate that two systems within the brain are involved in time discounting, noting, "When humans are offered the choice between rewards available at different points in time, the relative values of the options are discounted according to their expected delays until delivery. Using functional magnetic resonance imaging, we examined the neural correlates of time discounting while subjects made a series of choices between monetary reward options that varied by delay to delivery. We demonstrate that two separate systems are involved in such decisions. Parts of the limbic system associated with the midbrain dopamine system, including paralimbic cortex, are preferentially activated by decisions involving immediately available rewards. In contrast, regions of the lateral prefrontal cortex and posterior parietal cortex are engaged uniformly by intertemporal choices irrespective of delay. Furthermore, the relative engagement of the two systems is directly associated with subjects' choices, with greater relative fronto-parietal activity when subjects choose longer term options."

Kable and Glimcher [11] find, "Neuroimaging studies of decision-making have generally related neural activity to objective measures (such as reward magnitude, probability or delay), despite choice preferences being subjective. However, economic theories posit that decision-makers behave as though different options have different subjective values. Here we use functional magnetic resonance imaging to show that neural activity in several brain regions - particularly the ventral striatum, medial prefrontal cortex and posterior cingulate cortex-tracks the revealed subjective value of delayed monetary rewards. This similarity provides unambiguous evidence that the subjective value of potential rewards is explicitly represented in the human brain."

Peters and Buchel [18] write as follows: "During decision making, valuation of different types of rewards may involve partially distinct neural systems, but efficient choice behavior requires a common neural coding of stimulus value. We addressed this issue by measuring neural activity with functional magnetic resonance imaging while volunteers processed delayed and probabilistic decision options. Behaviorally, participants discounted both types of rewards in a hyperbolic manner, and discount rates, reflecting individual preferences, varied considerably between participants. Ventral striatum and orbitofrontal cortex showed a domain-general coding of subjective value regardless of whether rewards were delayed or probabilistic, strongly implicating these regions in the implementation of a common neural currency of value. In contrast, fronto-polar and lateral parietal cortex, as well as a region in the posterior

2 The exponential discounting is shown as $\mathrm{v}=\mathrm{Ve}^{-\mathrm{kD}}$ 
cingulate cortex only correlated with the value of delayed rewards, whereas superior parietal cortex and middle occipital areas only represented the value of probabilistic rewards. These results suggest a mechanism for the neural coding of subjective value in the human brain that is based on the combination of domain-general and domain-specific valuation networks."

Next, Marco-Pallares, Mohammadi, Samii and Munte [14] make the following assertion: "Humans discount the value of future rewards following a hyperbolic function and thus may prefer a smaller immediate reward over a larger delayed reward. Marked interpersonal differences in the steepness of this discounting function can be observed which can be quantified by the parameter $\mathrm{k}$ of the discount function. Here, we asked how differences in delay discounting behavior are reflected by brain activation patterns. Sixteen healthy participants were studied in a slow event-related functional magnetic resonance imaging (fMRI) experiment at 3T. In each trial, participants had to decide between a smaller but immediately available monetary reward (ranging between 14 and 84 Euro) and a larger delayed reward (26 to 89 Euro; delay 5 to 169 days) by button press. Participants had the chance to receive the reward corresponding to one of their decisions at the end of the experiment. As expected, participants differed widely with respect to the steepness of their discount function. By contrasting decisions at or near the individual participant's indifference point (as determined by parameter $\mathrm{k}$ ) with trials either well below or well above this point two different brain networks with opposing activation patterns were revealed: Trials below or above the indifference point were associated with activation in the ventral striatum and ventromedial prefrontal cortex, whereas decisions at the indifference point gave rise to activation in medial prefrontal cortex. The opposite effects in the two systems at individual indifference point were interpreted as a reflection of response conflict."

The characteristic finding of previous research on time discounting is the determination that when people carry out decision-making that entails time discounting (or probability discounting), there are the main parts of the brain that handles evaluation of subjective value, the part of the brain that handles evaluation of delayed value, and the part of the brain that evaluates value as part of a stochastic process, so that these parts of the brain that are carrying out the evaluation of value unique to each discount coexist. In other words, the brain contains a part that performs the central task in a given decision, as well as parts that differentiate between each task and process each uniquely; those parts combine to carry out specific (discounting) decisions. To put it conversely, the influence of each of those parts has the potential to change the discount.

\subsection{Overview of Interpersonal Discounting Research ${ }^{3}$}

One interpersonal discounting phenomenon, as we refer to in this paper, is the model that explains human altruism in orthodox terms, whereby the degree to which one discounts the value assigned to a given person varies depending on the degree of closeness to that person. An interesting additional analysis looks at altruism in the sense of asking the following: while the sharing of a reward with other people, as compared to keeping it to oneself, decreases the value of that reward, to what extent is the value of the reward discounted as the number of people with whom it is shared gradually increases? (Ito and Saeki, [8]; Ito, Saeki and Green, [9]). If we explain interpersonal discounting by once again using formula (1), $\mathrm{D}$ is the measure that indicates the degree of closeness and $\mathrm{k}$ is the individual parameter indicating altruism. According to the theory of shared value, $\mathrm{D}$ is the number of other people with whom the value is shared; $\mathrm{k}$ is the same individual parameter indicating altruism. In this paper, we will primarily be addressing the degree of closeness, but will touch on the latter aspect as well.

Let us take a look at some of the existing literature on interpersonal discounting. Jones and Rachlin [10] is a representative paper. According to the authors, "The amount of money a person was willing to forgo in order to give 75 dollars to another person decreased [was discounted] as a hyperbolic function of the perceived interpersonal distance between them. Similar hyperbolic functions have previously been shown to describe both time and probability discounting."

In Rachlin and Jones [20], the authors confirm the various characteristics of discounting functions, including time discounting, probability discounting, and the interpersonal discounting decision-making of individuals. They carried out three experiments. The first experiment concluded that the form of the discount function for interpersonal discounting is a hyperbolic curve. "In the second experiment, degree of interpersonal discounting was an increasing function of reward magnitude whereas degree of delay discounting was a decreasing function of reward magnitude. In the third experiment, the shape of the function relating delayed rewards to equally valued immediate rewards for another person was predicted from individual time discount and interpersonal discount functions."

Takahashi [22] proposes a novel interpersonal discounting model that utilizes the power law theory of physics.

Ostaszewski and Osinski [16] examine interpersonal discounting, focusing on the linkage between the value of

3 The discounting that we call "interpersonal" discounting is more commonly called "social" discounting in ordinary papers. The term "social" discounting is used in many papers listed in the references. However, since we use "social" discounting in a special meaning in this paper, we will call "social" discounting in ordinary papers as "interpersonal" discounting. 
the reward and the number of people with whom it is shared. "Based on evolutionary theory, individuals' interpersonal discounting rates were expected to depend on both reward amount and the type of relationship with the people with whom the reward would be shared. As predicted, smaller amounts were discounted less steeply than larger ones, and interpersonal discounting was steepest when sharing with strangers and shallowest when sharing with family."

Building on his 2010 paper, Takahashi [23] tentatively asserts that q-exponential interpersonal discounting functions are the most appropriate to interpersonal discounting.

Let us examine Yamakawa, Kanai, Matsumura and Naito [24], which is one of a small number of papers that analyzes reactions in the brain during interpersonal discounting decision-making. The authors focus on the following: "Across cultures, interpersonal relationships are often thought of, described, and acted out in terms of physical space. Does this cognitive mapping of interpersonal concepts (relationship between interpersonal distance of closeness and physical distance between the concerned parties) arise from shared brain resources for processing interpersonal and physical relationships? Using fMRI, they found that the tasks of evaluating interpersonal compatibility and of evaluating physical distances are involved in a common brain substrate in the parietal cortex. Their study shows the possibility of an analytic brain mechanism to process and represent complex networks of interpersonal relationships. Given parietal cortex's known role in constructing egocentric maps of physical space, such experimental findings may help to explain the linguistic, psychological and behavioral links between interpersonal and physical space." 4 Their research could even be called "spatial discounting" research.

Parkinson, Liu and Wheatley [17] expand upon the above-noted research. Yamakawa, Kanai, Matsumura and Naito [24] observed that decoding of interpersonal distance and physical distance is done in a common region of the brain, but Parkinson, Liu and Wheatley further found through experiments using fMRI that the inferior parietal lobule (IPL) is also involved in decoding for time.

Based on the above, in interpersonal discounting as well, the part of the brain that primarily controls tasks coexist with the part of the brain that carries out those tasks that are unique to interpersonal discounting and to its specific indices, and those two parts work together to carry out specific interpersonal discounting. Accordingly, the focus of our brain experiment alternately looks at time discounting and interpersonal discounting; based on that,

4 It is best to view Yamakawa, Kanai, Matsumura and Naito [24] as an example of applied research in the area of interpersonal discounting experimentation. This is because the original interpersonal discounting was the discounting of value based on the closeness of social relations, but this research expands that to the number of people who share the reward, and expands subjective closeness to physical distance. the first issue is to confirm the common portion of the brain that is used when making time discounting and interpersonal discounting decisions, and the portion of the brain that is unique to time discounting and interpersonal discounting decisions. By doing so, we will take the first step toward structurally clarifying the types of mechanisms through which various factors impact individual discounting decision-making.

\section{Hypotheses}

Section 1 and Section 2 of this paper have described the substance of the problem to be elucidated and indicated the neuro-science methodology for finding a clue to the solution. In this section we present in greater detail the operationalized hypotheses to be verified and an outline of the procedures for of experiments to verify the hypotheses:

Hypothesis 1 is that the discounting behavior of humans is hyperbolic discounting. This proposition can be indirectly inferred from the reaction within the brain of the experiment subjects when carrying out acts of discounting.

Hypothesis 2 is that managers (humans), when making assumptions about the discounting rate of others, tend to assume that the rate, whether it be time discounting or interpersonal discounting, is larger than the discount rate they decide upon and apply for themselves. This proposition will be confirmed through behavioral and brain experiment. In other words, the experiment subject's own discount rate and the rate they assume for others will be drawn out through behavioral experiment, showing that there is a significant statistical difference between the two.

Hypothesis 3 is that the brain regions that makes the experiment subject predict that the discount rate of another person is larger than their own discount rate are related to the brain regions that control recognition of others. More specifically, we predict based on research to date that it is the regions called the inferior parietal lobule (IPL), temporo-parietal junction (TPJ), or the superior parietal lobule (SPL, or the precuneus).

In the following section, we show the process of experiments and the results of experiments.

\section{Experiments and Results}

We reviewed the existing literature in the related fields in section 2 and having described in section 3 our hypothesis based on the conclusions of literature survey in section. We also presented an outline of the experiment procedures. So let us now turn to the specific procedures of the experiment we conducted in order to prove our hypothesis and describe the results. 


\subsection{Description of Experiment}

The experiment was conducted in June 2015 using a 3 Tesla (3T) fMRI. There were 25 subjects, all of whom were male and had either graduated from college or were in graduate school, with ages ranging from 23 to 32 . Because the subjects were not all graduates of the economics department, prior to the experimenting, the concept of discounting was explained using examples.

The brain experiment conducted for this paper began from the premise that, based on previous research findings, individual discounting behavior-both time discounting and interpersonal discounting-is dependent on hyperbolic discounting. We do not discuss how exponential discounting fits in. In this experiment, time discounting is handled through a set-up where through discounting, the longer the delay time, the more the monetary amount increases, while for interpersonal discounting, as closeness to the other person decreases, the amount of money decreases as well. Also, for time discounting, the non-discounted funds were set at $¥ 1,000$, while for interpersonal discounting, the standard was $¥ 10,000$. This was done in consideration of people’s sensitivity toward money. For time discounting, priority was placed on the sensitivity toward the comparison between the original funds and the funds plus the interest that accrues with time, while in the case of interpersonal discounting, the priority was on the sense that as the level of closeness decreases, the discount becomes larger and so the amount gets smaller. For that reason, the standard starting amount used in time discounting experiments was $¥ 1,000$, while the starting amount used in interpersonal discounting experiments began at $¥ 10,000$.

\subsection{Procedures}

\subsubsection{Specific Procedures Used in Time Discounting Experiment}

First, let us explain the experiment procedures based on the image that the subject views within the fMRI, starting with an explanation of the time discounting experiment.

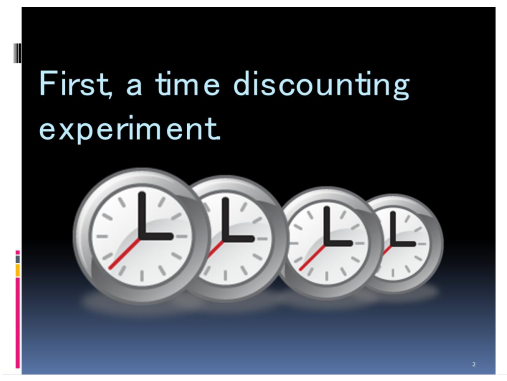

10 seconds

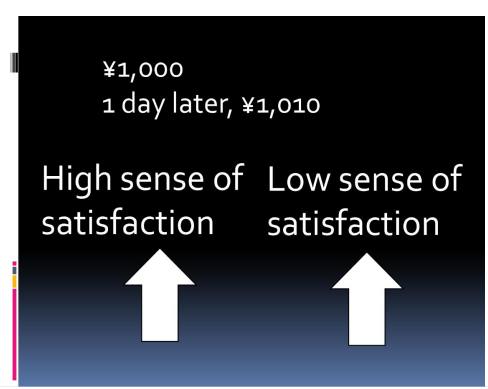

Until subject responds

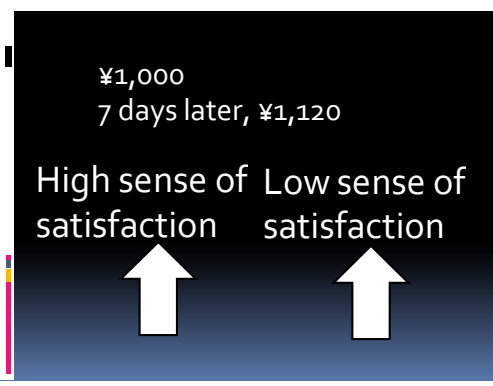

Until subject responds

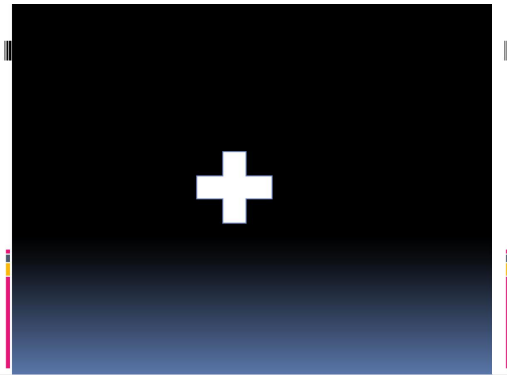

Random numbers (5-8 seconds)

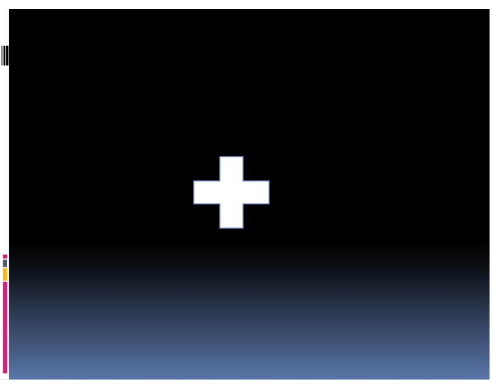

Random numbers (5-8 seconds)

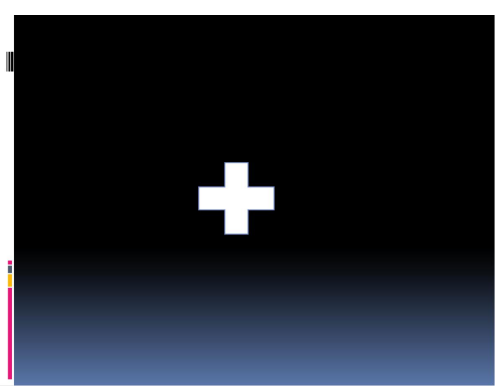

Random numbers (5-8 seconds)

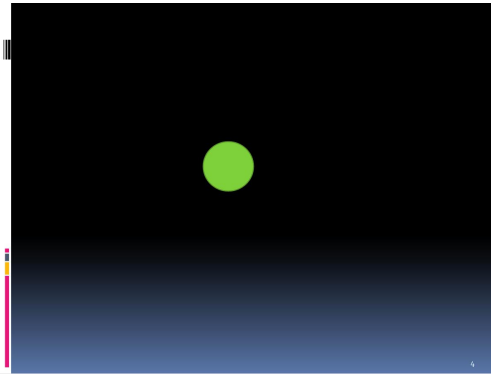

1 second

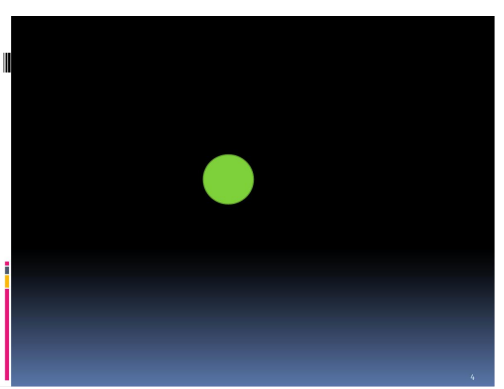

1 second

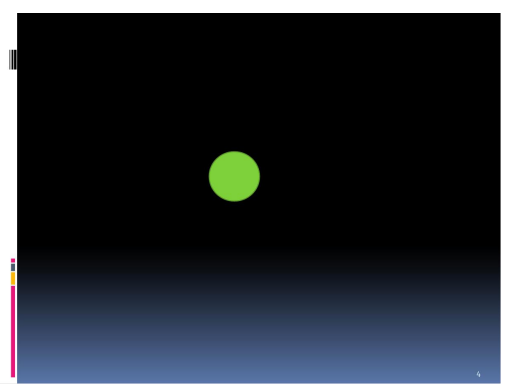

1 second

Figure 3. Illustration of time discounting stimuli 
An image like figure 3 is presented to the subject on an opaque screen using a software called Presentation, synchronized with the fMRI pulse. The test subject, while in the fMRI, is asked whether their level of satisfaction would be higher or lower if they received $¥ 1,010$ in one day's time as compared to their level of satisfaction receiving $¥ 1,000$ today. The image is stopped until the subject enters the response, and once the subject within the fMRI uses the button they are holding in their hand to select their satisfaction by choosing the arrow indicating either higher or lower, the white arrow becomes a red arrow.

If the subject chooses $¥ 1,010$, then the next delay option is seven days, and they will be asked how their level of satisfaction would compare if they received $¥ 1,140$ in seven days as opposed to $¥ 1,000$ today; would their satisfaction level be higher or lower? They are asked to choose:

$$
7 \text { days later } ¥ 1,000 \text { or } ¥ 1,120
$$

On the other hand, if they choose $¥ 1,000$ on the first day, then the question becomes:

$$
7 \text { days later } ¥ 1,000 \text { or } ¥ 1,065
$$

Similarly, the third delay option is 30 days, and if they chose $¥ 1,140$ in the 7 -days-later instance, they are asked:

$$
30 \text { days later } ¥ 1,000 \text { or } ¥ 1,500
$$

Or if they chose $¥ 1,070$, their choices are:

$$
30 \text { days later } ¥ 1,000 \text { or } ¥ 1,375
$$

That continues for seven times, asking the same types of questions about periods of delay ( 1 day later, 7 days, 30 days, 60 days, 90 days, 120 days, 150 days), moving on to the next when the button has been pushed.

Accordingly, the subject is required to respond by pushing the button seven times regarding alternatives to one undiscounted current value (in this example, $¥ 1,000$ ), and they are presented with four versions of that undiscounted current value $¥ 1,000, ¥ 3,000, ¥ 15,000$, and $¥ 40,000$. What we would like to call attention to once again here is that a given amount (e.g., ¥1,000) requires pushing the button seven times, but specifically it is a series of tasks such as the following: First, a comparison is required between the undiscounted $¥ 1,000$ and the discounted $¥ 1,010$ a day later, but the $¥ 1,010$ at that time represents the smallest $\mathrm{k}$ value $(\mathrm{k}=0.01)$ among the four types of hyperbolic discounting, which have differing individual parameters $(\mathrm{k}$ : here, it is a measure of the "degree of impatience") as prepared in advance with PC software in order to create the choices for the subject, and accordingly, it is the value on the hyperbolic curve indicating the smallest degree of impatience. The $¥ 1,000$ that is always shown above each question as the point of comparison is the $\mathrm{k}=0$ value. Next, we move to the choice of the discount amount seven days later. If the subject opted for $¥ 1,010$ one day later, then for the second question, when they are asked about an amount seven days later, a discount value of $\mathrm{k}=0.02$, or $¥ 1,120$, will be shown and they will be asked to choose between that or the current value of $¥ 1,000$. On the other hand, if the subject responded to the first question by selecting $¥ 1,000$, then the individual parameter of $\mathrm{k}=0.01$ will remain constant and the next choice displayed will be between $¥ 1,000$ and $¥ 1,065 \quad(\mathrm{k}=0.01)$. In this way, when the larger individual parameter is selected (i.e., the subject selects the "low level of satisfaction" option), the options for the next time lag will require a choice between $¥ 1,000$ and an amount based on a larger individual parameter. Five types of individual parameters that determine the discount rate, including $\mathrm{k}=0$, are incorporated into the program, along with seven time delays and four monetary amounts $(¥ 1,000, ¥ 3,000, ¥ 15,000$, and $¥ 40,000)$ that are changed and repeated (see fig. 4). Accordingly, during the subject's session in the fMRI, they are given seven types of time delays for four types of monetary amounts for a total of 28 responses.

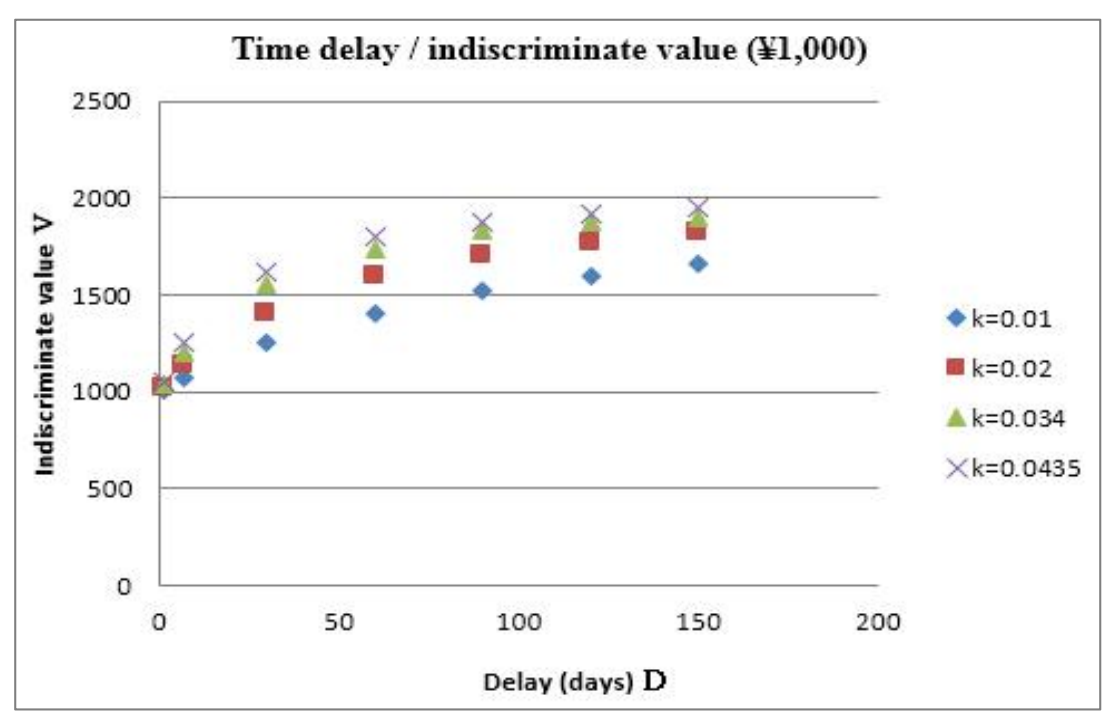

Figure 4. Assumed values for time discounting 


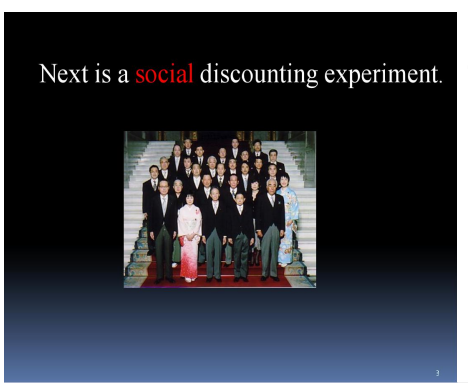

10 seconds

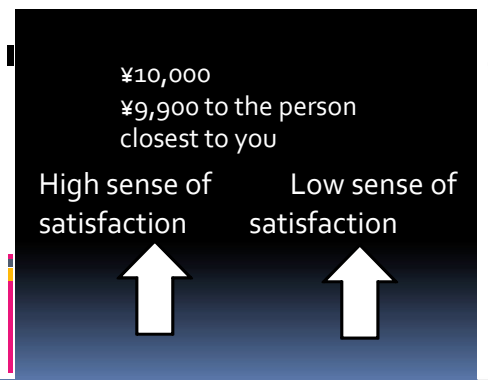

Until subject responds

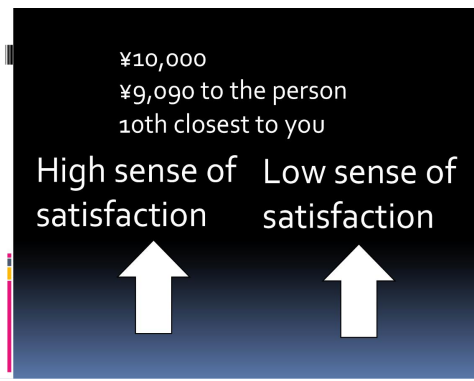

Until subject responds

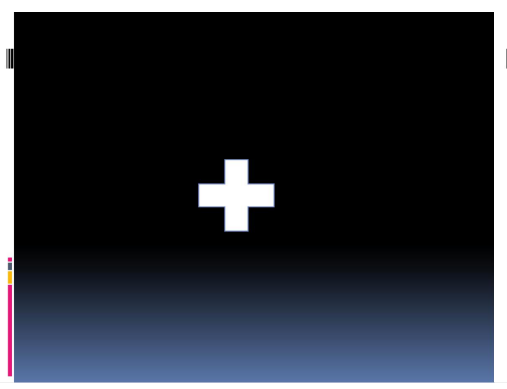

Random numbers (5-8 seconds)

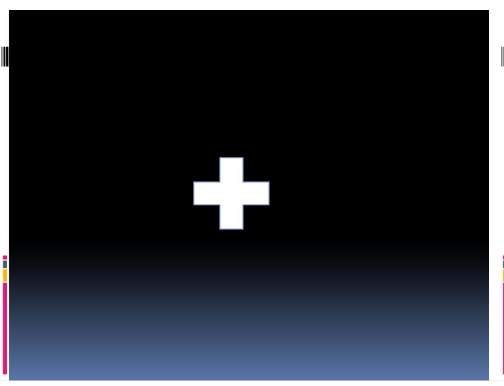

Random numbers (5-8 seconds)

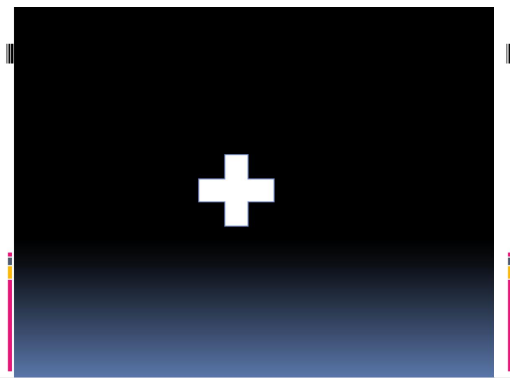

Random numbers (5-8 seconds)

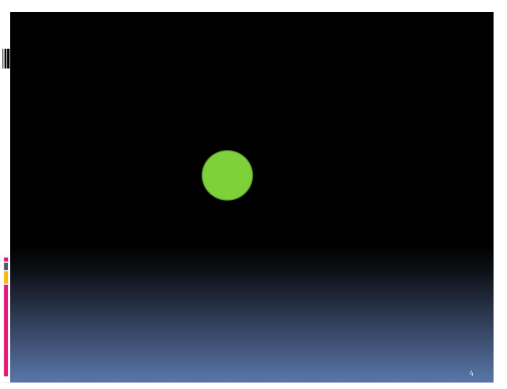

1 second

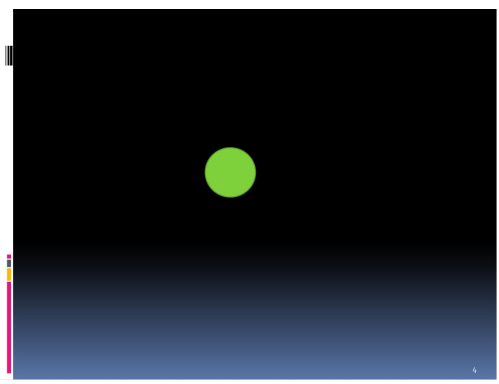

1 second

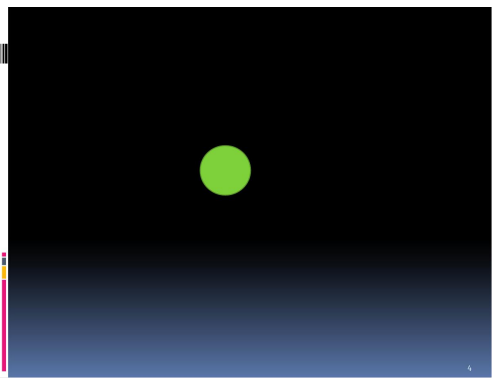

1 second

Figure 5. Illustration of interpersonal discounting stimuli

\subsubsection{Specific Procedures Used in Interpersonal Discounting Experiment}

Next, let us explain the interpersonal discounting experiment.

As seen in figure 5, the procedures are the same as for time discounting. Namely, the question posed to the subject is that they can have money, which if they use it themselves will be $¥ 10,000$ in value, but if they give $¥ 10,000$ of their own money to the person closest to them (for example, their mother), how much of the money available for their use would they forego? Here, the question is to make the following choice:

\section{Closest person $¥ 10,000$ or $¥ 9,900$}

A high degree of satisfaction means that the subject feels at least about the same satisfaction as if they used the money themselves, so it is alright to discount it a bit and thus they choose $¥ 9,900$. Those who answer that they feel a low degree of satisfaction indicate that they would feel a low sense of satisfaction in giving $¥ 9,900$ to another person as compared to using $¥ 10,000$ themselves, and this approximates choosing the $¥ 10,000$ without a discount.
When they push the white arrow button, it changes to a red arrow. Next, if the option for the 1st closest person was $¥ 9,900$, then when choosing an amount to give the person who is 10 th closest to the subject, they will be asked to compare using $¥ 10,000$ themselves or $¥ 9,090$ $(\mathrm{k}=0.01)$ :

\section{0th closest person $¥ 9,090$ or $¥ 8,300$}

In this choice, a high degree of satisfaction means that the subject feels at least about the same satisfaction as if they used the money themselves, so it is alright to discount it a bit and thus they choose $¥ 8,300$. Those who answered that they feel a low degree of satisfaction indicate that they would feel a low sense of satisfaction in giving $¥ 9,090$ to another person as compared to using $¥ 10,000$ themselves, and thus this approximates choosing the $¥ 10,000$ without a discount.

In the case of the 25 th closest person, if the subject chose $¥ 8,300$ for the 10 th closest person, then they are asked:

25th closest person $¥ 6,600$ or $¥ 5,400$ 
And if they chose $¥ 9,090$ for the 10th closest person, then they are presented with this choice:

25 th closest person $¥ 8,000$ or $¥ 6,600$

And it continues on, with the ranks for closeness being 1st, 10th, 25th, 50th, 75th, 100th, and 125th.

Accordingly, for interpersonal discounting as well, for one given amount (in this example, $¥ 10,000$ ), the subject is asked to push the button seven times to choose between two options, and they are presented with four starting amounts ( $¥ 10,000, ¥ 30,000, ¥ 150,000$, and $¥ 400,000$ ). As in the previous case, what should be noted here is that while the subject is asked to push the button seven times for each amount (e.g., ¥10,000), more specifically that entails the following: First, the initial person is presented with the undiscounted $¥ 10,000$ and the discounted $¥ 9,900$, and the $¥ 9,900$ at that point is the smallest $\mathrm{k}$ value $(\mathrm{k}=0.01$; not including the undiscounted value of $\mathrm{k}=0$ ) among the four types of hyperbolic discounting, which have differing individual parameters $(\mathrm{k})$ as prepared in advance with computer software in order to create the choices for the subject, and accordingly it is the value on the hyperbolic curve indicating the smallest "degree of selfishness." The $¥ 10,000$ that is always shown above each question as the point of comparison is, needless to say, the undiscounted $\mathrm{k}=0$ value. Next, we move to the choice of the discount amount for the person who ranks 10th in degree of closeness to the subject. If the subject opted for $¥ 9,900$ in the case of the 1st closest person, then for the second question, when they are asked about the 10th closest person, then the amount displayed in order to be compared with $¥ 9,090$ - the $\mathrm{k}=0$ value for the 10 th closest person-is $¥ 8,300$, which is the second smallest degree of selfishness on the hyperbolic curve and is set according to the individual parameter of $\mathrm{k}=0.02$. On the other hand, if the subject responded to the first question by selecting $¥ 10,000$, then the next choice displayed will be between $¥ 10,000$ and $¥ 9,090 \quad(\mathrm{k}=0.01)$. In this way, when the larger individual parameter is selected, the options for the person at the next degree of closeness will require a choice between a discounted amount corresponding to that degree of closeness along the hyperbolic curve as set using the same parameter and an amount based on an individual parameter that is one level larger. Similarly to the time discounting experiment, there are five types of individual parameters that determine the discount rate (including $\mathrm{k}=0$ ) that are incorporated into the program, along with seven degrees of closeness and four monetary amounts ( $¥ 10,000, ¥ 30,000, ¥ 150,000$, and $¥ 400,000$ ) that are changed and repeated (see fig. 6). Accordingly, during the test subject's session in the fMRI, they will give a total of 28 responses.

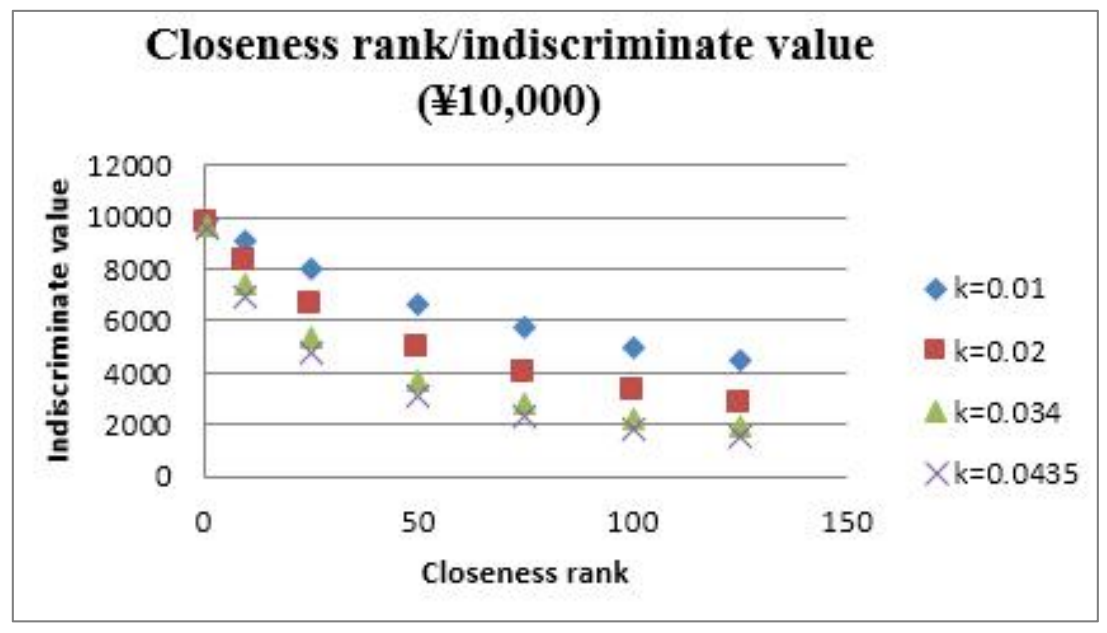

Figure 6. Assumed values for interpersonal discounting 


\subsubsection{Specific Procedures Used in Interpersonal} Discounting Experiment

Moreover, in addition to the issues of time and interpersonal discounting, we assumed the existence of a type of social average in the form of the hypothetical "market," which is always the focus of consideration, and tried to examine the impact on discounting of its hypothetical existence. Accordingly, we continue on by having the subject imagine the discount value they think is established in a hypothetical "market" and then ask them to revise their discount so that it comes closer to that value; the two types of time and interpersonal discounting experiments are then repeated. In that case, the subject is told in advance that the hypothetical social average (average market value) has been input into the program in advance and the person who comes nearest to that value will get a bonus. As a result, the subjects inside the fMRI carry out the task of pushing the button for one of the two options 112 times $(7 \times 4 \times 4)$. Figure 7 shows the stimulus images for time discounting that considers social averages, and the image on the left is inserted in place of the first slide of the series of stimulus images noted above. The image on the right is shown following the completion of one session and shown as its results. ${ }^{5}$ Social discounting that considers social averages is conducted in the same way, and thus the images are not shown here.

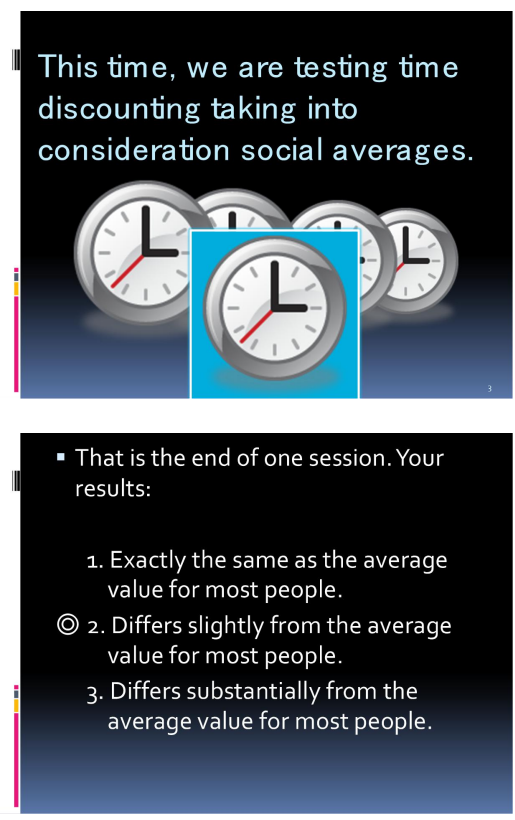

Figure 7. Auxiliary images for the social average experiment

By carrying out the experiment described above on four types of discounting processes-time discounting and interpersonal discounting under different circumstances and then both forms of discounting in consideration of the social average (modeled on a market) — and measuring the

5 Time discounting that considers social averages is repeated 4 times, so it does not show whether the discrepancy is larger or smaller than the social average value. responses within the brain in each case, we would like to answer the question of how, under the four types of conditions, the activation regions of the brain differ, or whether there are also common regions. In particular, our primary focus is the question of under what conditions and to what extent the areas of the brain related to awareness of others and of society are activated when thinking about discounting.

There is one point that we must note clearly here. We did not indicate to the subjects at the time of discounting experiment that it was hyperbolic discounting experiment in advance. The subjects handled the task of the selection of discount values in a matter-of-fact manner. Thus, we can assume that the conditions of the brain activation that were observed were the normal intracerebral reaction that occurs when people carry out discounting tasks.

\subsection{Results of Experiments}

\subsubsection{Results and Analysis of Behavioral Experiment}

Twenty-five subjects participated in the fMRI experiment described above. Based on the experiment results we determined each person's specific individual parameter $(\mathrm{k})$ in order to establish the hyperbolic curve that shows the five different degrees of altruism (one of which is $\mathrm{k}=0$ ), which explains the subject's discounting behavior in each of the four sessions. The curve for the greatest level of altruism is $\mathrm{k}=0$, which is called curve 0 , and as the level of altruism decreases in turn, those curves are numbered as $1,2,3$, and 4 . The estimation method is simple. As noted in the explanations of the experiment, the choice between two options is made in seven stages, and the subject usually, by gradually choosing a larger (smaller) amount was in fact choosing the underlying individual parameter $(\mathrm{k})$, and in the end generally settles on a certain parameter $(\mathrm{k})$. The criterion for determining that the subject had settled down and chosen the relevant parameter is that, if in the final stage of the seven selections, they choose an amount two or more times in a row that falls within the specified hyperbolic functions set by the individual parameter, then that is taken to be the individual subject's discounting function. The average curve (1-5) selected by the 25 subjects is shown in table $1 .^{6}$ The smaller the value, the higher the level of altruism, while the larger the value, the higher the level of selfishness.

What stands out in table 1 is that when social conditions are added, we see that the discounting rate sharply rises (significant level=0.01). Also, prior to adding in the social conditions, interpersonal discounting is larger than time discounting. The effect of social conditions is larger on time discounting.

6 The order in which the testing was done was time discount, interpersonal discount, time/social average discount, social/social average discount, and thus we believe it is possible to ignore the effect of the order. 
Table 1. Average value of four discounts disregarding the monetary amount

\begin{tabular}{|l|l|}
\hline Time/individual discount & 1.261 \\
\hline Interpersonal/individual discount & 1.613 \\
\hline Time/social discount & 2.863 \\
\hline Interpersonal/social discount & 2.125 \\
\hline
\end{tabular}

( 0 : individual parameter $=0 \quad 1$ : individual parameter $=0.012:$ individual parameter $=0.02 \quad 3$ : individual parameter $=0.034 \quad 4:$ individual parameter $=0.0435$

Next, table 2 shows the relationship between the discount rate and the monetary amount presented.

What is notable in table 2 is that the larger the amount presented, the smaller the discount rate becomes (significant level=0.05). Here as well, the discount rate is higher when considering the sociality of the question. The impact on time discounting is particularly large. And the rate increase occurs when considering the sociality factor becomes larger as the amount increases.

Based on the above, it can be said that a large rise in the discount rate is seen when sociality is added to both time and interpersonal discounting, and that impact of sociality gets larger-or in other words, the discount rate falls less - as the monetary amount increases. If we look at the results as they relate to the hypothesis we presented for the management problem, it would suggest that the larger the scale of the company - and accordingly the scale of profits - the more it may cause the discount rate to rise when sociality is added in, or in other words, when an executive see that a competitor with a different behavior pattern has entered the economy.

\subsubsection{Results and Analysis of the Brain Testing}

Next, let us analyze our hypothesis by adding the results of the brain experiment to the results of the behavioral experiment described above. The findings of the brain experiment can be seen in the images below. First, figure 8 shows the areas of activation of the entire brain during the discounting experiment. Also, Table 3 presents the location, volume and significance levels for the activated regions.

Table 2. Average discount rate by monetary amount

\begin{tabular}{|c|c|c|c|}
\hline Time/individual discount & 2.068 & 1.224 & 0.925 \\
\hline Interpersonal/individual discount & 2.615 & 1.379 & 1.043 \\
\hline Time/social discount & 2.727 & 2.851 & 2.913 \\
\hline Interpersonal/social discount & 2.342 & 2.311 & 2.093 \\
\hline Average & 2.438 & 1.941 & 2.143 \\
\hline Discount conditions & \multicolumn{2}{|c|}{ Amount 1 < Amount 2 < Amount 3< Amount 4 } \\
\hline
\end{tabular}

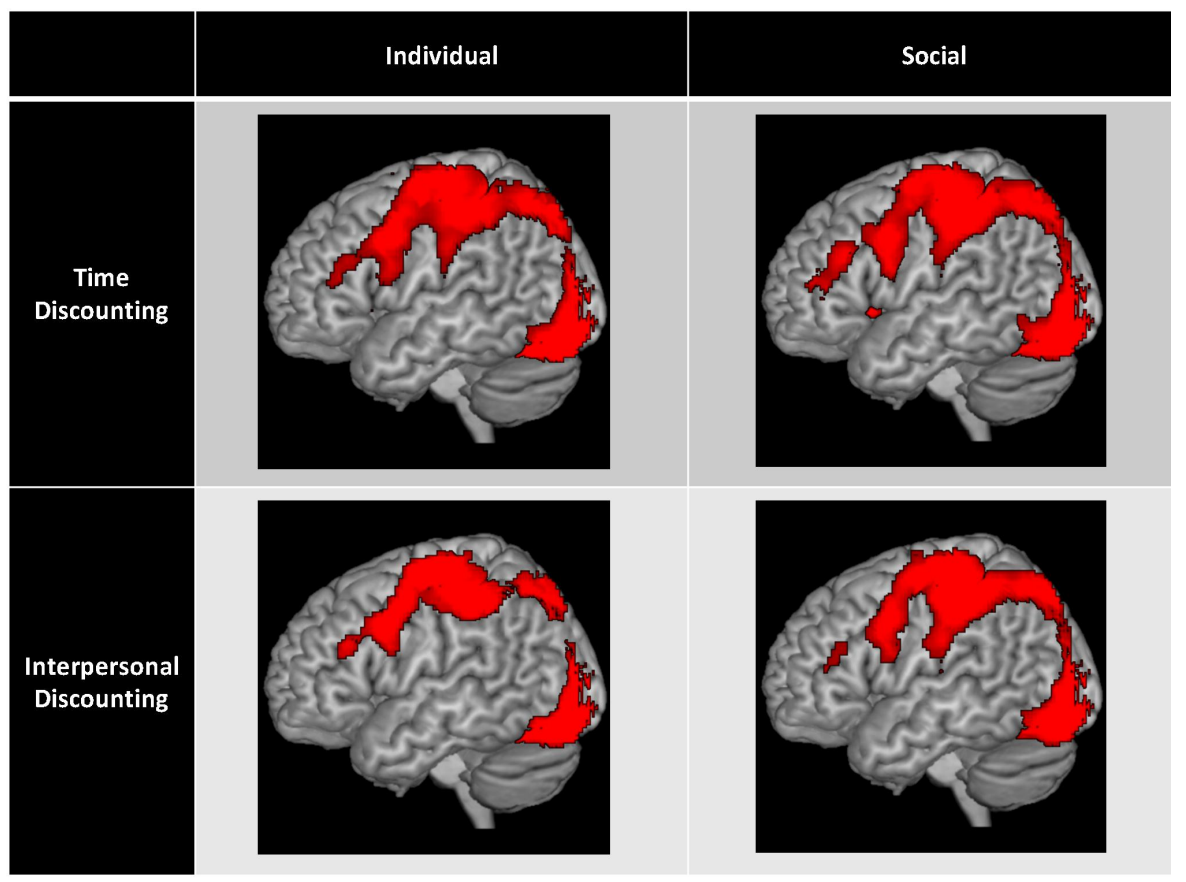

Figure 8. Areas activated within the brain during discounting experiment ${ }^{7}$

7 Activated parts are listed as Table 3. The data was derived from SPM-8. SPM-8 is a software package which has been designed for the analysis of brain imaging data sequences. Statistical Parametric Mapping (SPM) refers to the construction and assessment of spatially extended statistical 
Table 3. Summary of activations by contrast in Figure 8

time-individual

\begin{tabular}{|c|c|c|c|c|c|c|}
\hline & \multicolumn{4}{|c|}{ Coordinates for max.voxel } & \multirow{2}{*}{$\begin{array}{c}\text { Number of } \\
\text { voxels }\end{array}$} & \multirow{2}{*}{$\begin{array}{c}\text { peak } \\
T\end{array}$} \\
\hline & Region & $\mathbf{x}$ & $\mathbf{y}$ & $\mathbf{z}$ & & \\
\hline \multirow[t]{3}{*}{$\mathrm{L}$} & Inferior parietal lobule & -44 & -30 & 50 & 8818 & 10.588 \\
\hline & & -52 & -22 & 54 & & 10.449 \\
\hline & & -40 & -20 & 58 & & 9.316 \\
\hline \multirow[t]{3}{*}{$\mathrm{R}$} & Fusiform gyrus & 28 & -44 & -20 & 3536 & 9.333 \\
\hline & & 20 & -56 & -24 & & 6.304 \\
\hline & & 6 & -70 & -26 & & 6.061 \\
\hline \multirow[t]{3}{*}{$\mathrm{R}$} & Postcentral gyrus & 50 & -30 & 52 & 1256 & 8.091 \\
\hline & & 54 & -22 & 44 & & 6.796 \\
\hline & & 62 & -14 & 34 & & 5.159 \\
\hline \multirow[t]{2}{*}{$\mathrm{L}$} & Inferior frontal gyrus & -40 & 24 & 24 & 577 & 7.914 \\
\hline & & -42 & 38 & 12 & & 5.101 \\
\hline \multirow[t]{3}{*}{$\mathrm{L}$} & Precentral gyrus & -54 & 6 & 38 & 2505 & 7.841 \\
\hline & & -52 & 8 & 14 & & 6.926 \\
\hline & & -32 & 18 & 10 & & 6.161 \\
\hline \multirow[t]{3}{*}{$\mathrm{R}$} & Putamen & 26 & 16 & 8 & 1816 & 6.873 \\
\hline & & 20 & 10 & 4 & & 6.101 \\
\hline & & 52 & 8 & 20 & & 5.657 \\
\hline \multirow[t]{3}{*}{$\mathrm{L}$} & Inferior temporal gyrus, Fusiform & -52 & -50 & -12 & 479 & 5.920 \\
\hline & & -44 & -50 & -20 & & 5.601 \\
\hline & & -34 & -48 & -28 & & 5.157 \\
\hline \multirow[t]{3}{*}{$\mathrm{R}$} & Precentral gyrus & 28 & -14 & 64 & 290 & 5.834 \\
\hline & & 20 & -2 & 54 & & 4.868 \\
\hline & & 24 & -4 & 62 & & 4.032 \\
\hline \multirow[t]{3}{*}{$\mathrm{R}$} & Middle Occipital gyrus & 30 & -78 & 34 & 387 & 4.881 \\
\hline & & 32 & -76 & 42 & & 4.372 \\
\hline & & 18 & -74 & 54 & & 3.789 \\
\hline
\end{tabular}


time-social

\begin{tabular}{|c|c|c|c|c|c|c|}
\hline & \multicolumn{4}{|c|}{ Coordinates for max.voxel } & \multirow{2}{*}{$\begin{array}{c}\text { Number of } \\
\text { voxels }\end{array}$} & \multirow{2}{*}{$\frac{\text { peak }}{\mathrm{T}}$} \\
\hline & & $\mathrm{x}$ & $\mathrm{y}$ & $\mathrm{z}$ & & \\
\hline \multirow[t]{3}{*}{$\mathrm{R}$} & Putamen & 22 & 10 & 2 & 3229 & 9.870 \\
\hline & & 50 & 8 & 2 & & 6.462 \\
\hline & & 52 & -26 & 52 & & 5.784 \\
\hline \multirow[t]{3}{*}{$\mathrm{L}$} & Inferior parietal lobule & -52 & -26 & 48 & 6254 & 9.439 \\
\hline & & -46 & -24 & 58 & & 8.547 \\
\hline & & -44 & -30 & 48 & & 8.039 \\
\hline \multirow[t]{3}{*}{$\mathrm{R}$} & Inferior temporal gyrus & 54 & -68 & -8 & 565 & 8.551 \\
\hline & & 42 & -84 & 4 & & 5.249 \\
\hline & & 52 & -50 & -12 & & 4.469 \\
\hline \multirow[t]{3}{*}{$\mathrm{L}$} & Inferior frontal gyrus & -46 & 32 & 20 & 578 & 6.111 \\
\hline & & -44 & 38 & 14 & & 5.895 \\
\hline & & -40 & 32 & 30 & & 4.444 \\
\hline \multirow[t]{3}{*}{$\mathrm{L}$} & Middle Occipital gyrus & -44 & -84 & 4 & 320 & 5.458 \\
\hline & & -36 & -90 & 4 & & 4.658 \\
\hline & & -48 & -68 & -8 & & 4.081 \\
\hline \multirow[t]{3}{*}{$\mathrm{R}$} & Cerebelum & 14 & -56 & -24 & 629 & 5.241 \\
\hline & & 36 & -50 & -26 & & 5.033 \\
\hline & & 24 & -52 & -24 & & 4.875 \\
\hline \multirow[t]{3}{*}{$\mathrm{R}$} & Middle Frontal gyrus & 22 & 16 & 46 & 882 & 5.054 \\
\hline & & -8 & 16 & 42 & & 5.035 \\
\hline & & -4 & 4 & 48 & & 4.870 \\
\hline \multirow[t]{3}{*}{$\mathrm{L}$} & Thalamus & -12 & -14 & -4 & 145 & 4.288 \\
\hline & & -16 & -22 & -2 & & 4.202 \\
\hline & & -16 & -20 & 8 & & 3.811 \\
\hline
\end{tabular}


interpersonal-individual

\begin{tabular}{|c|c|c|c|c|c|c|}
\hline & \multicolumn{4}{|c|}{ Coordinates for max.voxel } & \multirow{2}{*}{$\begin{array}{c}\text { Number of } \\
\text { voxels }\end{array}$} & \multirow{2}{*}{$\begin{array}{c}\text { peak } \\
\mathrm{T}\end{array}$} \\
\hline & & $\mathrm{x}$ & $\mathrm{y}$ & $\mathrm{z}$ & & \\
\hline \multirow[t]{3}{*}{$\mathrm{L}$} & Postcentral gyrus & -52 & -24 & 54 & 2217 & 8.617 \\
\hline & & -36 & -20 & 66 & & 7.580 \\
\hline & & -40 & -30 & 48 & & 7.529 \\
\hline \multirow[t]{3}{*}{$\mathrm{R}$} & Inferior Temporal gyrus & 50 & -56 & -12 & 408 & 6.266 \\
\hline & & 44 & -62 & -16 & & 4.929 \\
\hline & & 32 & -58 & -24 & & 4.672 \\
\hline \multirow[t]{2}{*}{$\mathrm{R}$} & Postcentral gyrus, & 54 & -26 & 50 & 443 & 6.075 \\
\hline & (Inferior parietal lobule, Intraparietal sulcus) & 44 & -42 & 48 & & 5.102 \\
\hline $\mathrm{L}$ & $\begin{array}{l}\text { Putamen } \\
\end{array}$ & -16 & 10 & 6 & 116 & 5.823 \\
\hline \multirow[t]{3}{*}{$\mathrm{R}$} & Inferior parietal lobule, & 38 & -82 & 30 & 562 & 5.427 \\
\hline & (Intraparietal sulcus) & 34 & -64 & 48 & & 4.326 \\
\hline & & 30 & -68 & 40 & & 3.752 \\
\hline \multirow[t]{3}{*}{$\mathrm{L}$} & Thalamus & -4 & -20 & 2 & 319 & 5.321 \\
\hline & & 8 & -22 & 6 & & 5.123 \\
\hline & & -10 & -12 & 2 & & 4.588 \\
\hline $\mathrm{L}$ & Precentral gyrus & -52 & 6 & 30 & 278 & 5.141 \\
\hline \multirow[t]{3}{*}{$\mathrm{L}$} & Posterior Medial frontal & -8 & -8 & 56 & 433 & 4.690 \\
\hline & & -2 & 10 & 52 & & 4.661 \\
\hline & & -6 & 0 & 52 & & 4.538 \\
\hline \multirow[t]{3}{*}{$\mathrm{L}$} & Middle Occipital gyrus & -30 & -90 & 12 & 462 & 4.405 \\
\hline & & -28 & -76 & 30 & & 4.329 \\
\hline & & -34 & -82 & 20 & & 4.178 \\
\hline
\end{tabular}

interpersonal-social

\begin{tabular}{|c|c|c|c|c|c|c|}
\hline & \multicolumn{4}{|c|}{ Coordinates for max.voxel } & \multirow{2}{*}{$\begin{array}{c}\text { Number of } \\
\text { voxels }\end{array}$} & \multirow{2}{*}{$\begin{array}{c}\text { peak } \\
T\end{array}$} \\
\hline & & $\mathrm{x}$ & $\mathrm{y}$ & $\mathrm{z}$ & & \\
\hline \multirow[t]{3}{*}{ L } & Inferior parietal lobule & -42 & -34 & 46 & 4438 & 9.816 \\
\hline & & -36 & -20 & 66 & & 9.590 \\
\hline & & -44 & -24 & 60 & & 8.713 \\
\hline $\mathrm{R}$ & Inferior temporal gyrus & 48 & -58 & -12 & 482 & 7.246 \\
\hline \multirow[t]{3}{*}{$\mathrm{R}$} & Intraparietal sulcus, & 54 & -26 & 50 & 1914 & 6.669 \\
\hline & (Postcentral gyrus, Middle Occipital gyrus, & 42 & -80 & 18 & & 5.551 \\
\hline & Superior parietal lobule, Inferior parietal lobule) & 44 & -46 & 58 & & 5.356 \\
\hline \multirow[t]{3}{*}{$\mathrm{L}$} & $\begin{array}{l}\text { Superior Frontal gyrus } \\
\end{array}$ & -18 & 0 & 52 & 636 & 5.964 \\
\hline & & -8 & 10 & 50 & & 5.026 \\
\hline & & -8 & -10 & 56 & & 4.422 \\
\hline $\mathrm{L}$ & Putamen & -20 & 2 & 10 & 120 & 5.069 \\
\hline \multirow[t]{3}{*}{$\mathrm{R}$} & Thalamus & 6 & -16 & -2 & 244 & 4.976 \\
\hline & & -6 & -16 & -4 & & 3.996 \\
\hline & & -6 & -26 & -2 & & 3.933 \\
\hline \multirow[t]{2}{*}{$\mathrm{R}$} & Precentral gyrus & 54 & 10 & 32 & 108 & 4.935 \\
\hline & & 56 & 8 & 18 & & 3.674 \\
\hline \multirow[t]{3}{*}{$\mathrm{L}$} & Precentral gyrus & -54 & 6 & 30 & 285 & 4.791 \\
\hline & & -46 & 0 & 32 & & 4.686 \\
\hline & & -56 & 6 & 40 & & 3.887 \\
\hline \multirow[t]{3}{*}{$\mathrm{R}$} & Precentral gyrus, (Superior Frontal gyrus) & 28 & -6 & 56 & 197 & 4.770 \\
\hline & & 20 & 12 & 48 & & 4.692 \\
\hline & & 26 & 2 & 54 & & 4.395 \\
\hline \multirow[t]{3}{*}{$\mathrm{R}$} & Cerebelum & 16 & -64 & -42 & 197 & 4.548 \\
\hline & & 10 & -72 & -40 & & 4.215 \\
\hline & & 18 & -62 & -34 & & 4.176 \\
\hline \multirow[t]{3}{*}{$\mathrm{L}$} & Middle Occipital gyrus & -36 & -88 & 12 & 236 & 4.527 \\
\hline & & -40 & -80 & 4 & & 4.377 \\
\hline & & -36 & -78 & 14 & & 4.197 \\
\hline
\end{tabular}


When conducting the fMRI experiment, we did not convey to the subject whether the discount values presented were calculated using exponential discounting or hyperbolic discounting. As a result, the areas of brain activation shown here are the standard areas of activation that occur when a human carries out discounting behavior. Based on dual-process theory (Frederick [6]), discounting behavior is prescribed in the interaction between the short-term pursuit of profit, which is regulated by the system of emotions generally controlled by the limbic system, and the pursuit of long-term benefit controlled by the cerebral neocortex.
If the limbic system that controls emotion is activated, it indicates a strong hyperbolic discounting tendency toward short-term results, while activation of the cerebral neocortex indicates a strong exponential discounting tendency toward long-term results. Based on our fMRI image findings, we were able to confirm that hyperbolic discounting elements are strongly related to human discounting behavior.

Next, figures 9 and 10 summarize the characteristics of our experiment in two 4D spatial images. Table 4 presents the location, volume and significance levels for the activated regions.

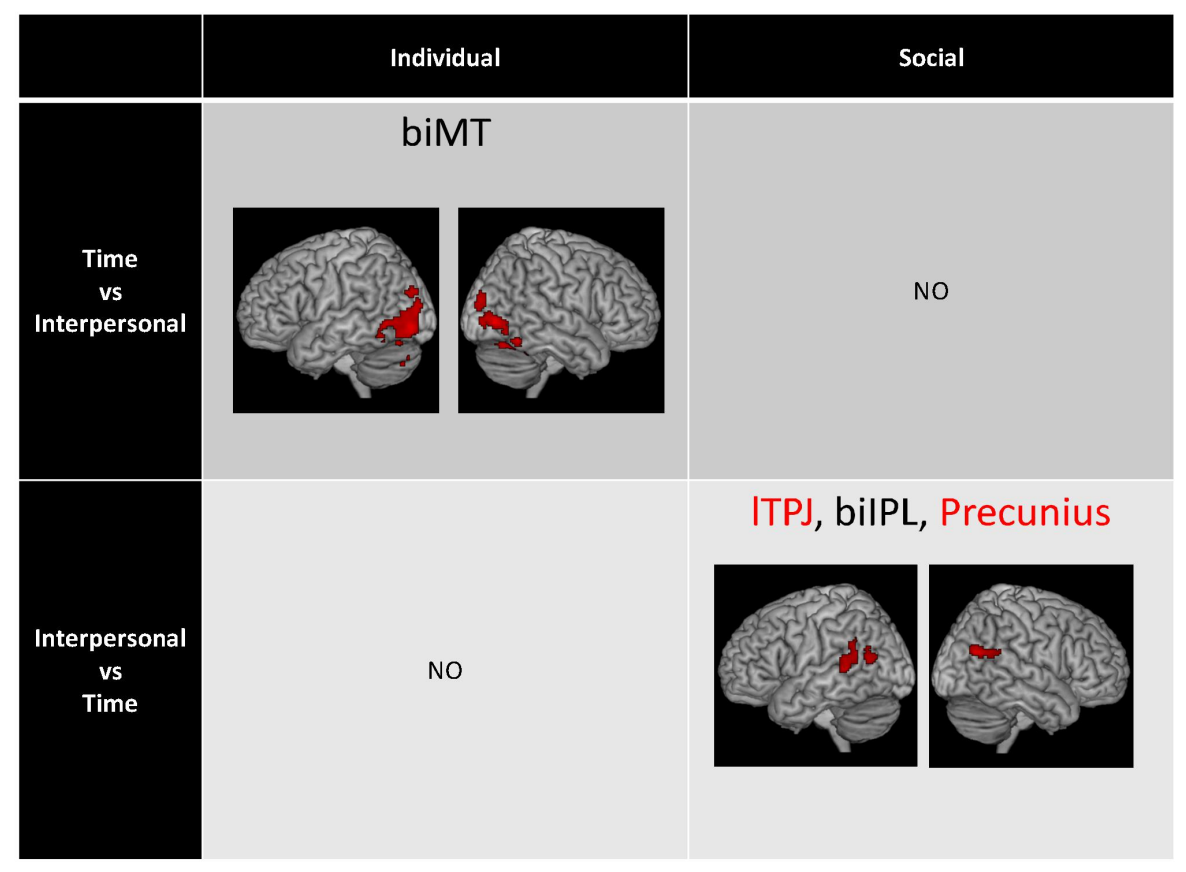

biMT: bilateral middle temporal

ITPJ: left Temporo-parietal junction

biIPL: bilateral inferior parietal lobule

Figure 9. Differences of Brain Activation Areas between two discounting experiments (1) 


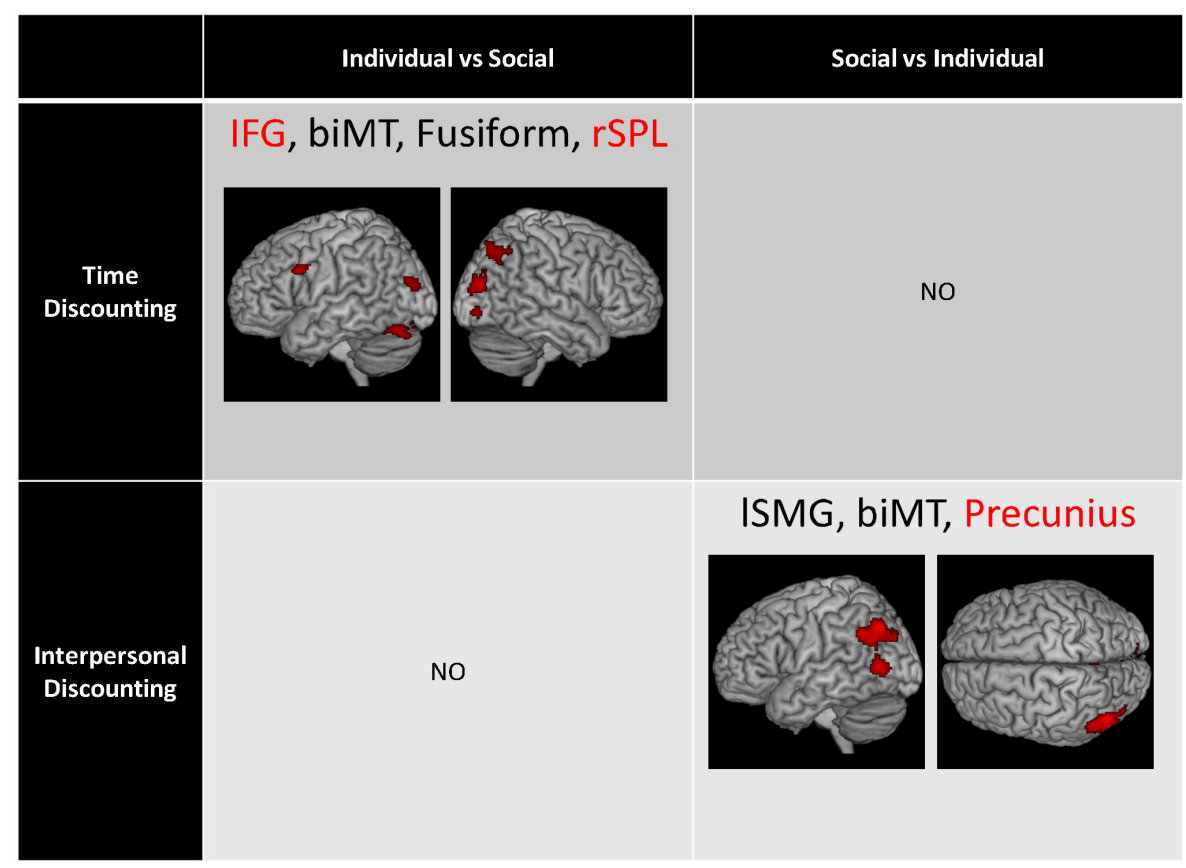

IFG: Inferior frontal gyrus

rSPL: right Superior parietal lobule

ISMG: left supramarginal gyrus

Figure 10. Differences of Brain Activation Areas between two discounting experiments (2)

Table 4. Summary of activations by contrast in Figure 9 and 10.

Individual_(time-interpersonal) in Figure 9

\begin{tabular}{|c|c|c|c|c|c|c|}
\hline & \multicolumn{4}{|c|}{ Coordinates for max.voxel } & \multirow{2}{*}{$\begin{array}{c}\text { Number of } \\
\text { voxels }\end{array}$} & \multirow{2}{*}{$\frac{\text { peak }}{\mathrm{T}}$} \\
\hline & & $\mathrm{x}$ & $\mathrm{y}$ & $\mathrm{z}$ & & \\
\hline \multirow[t]{3}{*}{$\mathrm{L}$} & $\mathrm{ACC}$ & -2 & 44 & 18 & 621 & 5.915 \\
\hline & & 0 & 58 & 6 & & 5.427 \\
\hline & & -12 & 48 & 0 & & 4.630 \\
\hline $\mathrm{R}$ & Cuneus & 12 & -86 & 40 & 281 & 5.795 \\
\hline \multirow[t]{2}{*}{$\mathrm{L}$} & Cuneus & -6 & -92 & 24 & & 4.917 \\
\hline & & 6 & -92 & 20 & & 4.306 \\
\hline \multirow[t]{3}{*}{$\mathrm{R}$} & Superior Parietal Lobule & 28 & -56 & 68 & 222 & 5.631 \\
\hline & & 12 & -66 & 68 & & 4.629 \\
\hline & & 38 & -46 & 64 & & 3.626 \\
\hline \multirow[t]{3}{*}{$\mathrm{R}$} & Supramarginal Gyrus & 48 & -26 & 34 & 317 & 5.523 \\
\hline & & 46 & -36 & 34 & & 4.813 \\
\hline & & 36 & -36 & 32 & & 4.790 \\
\hline \multirow[t]{3}{*}{$\mathrm{R}$} & Cerebelum & 26 & -48 & -22 & 148 & 5.140 \\
\hline & & 22 & -28 & -22 & & 4.754 \\
\hline & & 20 & -38 & -22 & & 4.266 \\
\hline \multirow[t]{3}{*}{$\mathrm{L}$} & Superior Parietal Lobule & -16 & -56 & 70 & 402 & 4.897 \\
\hline & & -28 & -52 & 72 & & 4.680 \\
\hline & & -46 & -38 & 54 & & 4.383 \\
\hline \multirow[t]{2}{*}{$\mathrm{L}$} & Supramarginal Gyrus & -60 & -22 & 40 & 116 & 4.608 \\
\hline & & -64 & -24 & 28 & & 4.108 \\
\hline
\end{tabular}


Social (interpersonal-time) in Figure 9

\begin{tabular}{|c|c|c|c|c|c|c|}
\hline & \multicolumn{4}{|c|}{ Coordinates for max.voxel } & \multirow{2}{*}{$\begin{array}{c}\text { Number of } \\
\text { voxels }\end{array}$} & \multirow{2}{*}{$\frac{\text { peak }}{\mathrm{T}}$} \\
\hline & & $\mathrm{x}$ & $\mathrm{y}$ & $\mathrm{z}$ & & \\
\hline \multirow[t]{3}{*}{$\mathrm{R}$} & Intraparietal sulcus, & 32 & -60 & 46 & 217 & 4.928 \\
\hline & (Angular gyrus, Inferior parietal lobule) & 32 & -42 & 44 & & 4.191 \\
\hline & & 44 & -56 & 50 & & 3.915 \\
\hline
\end{tabular}

time_(individual-social) in Figure 10

\begin{tabular}{|c|c|c|c|c|c|c|}
\hline & \multicolumn{4}{|c|}{ Coordinates for max.voxel } & \multirow{2}{*}{$\begin{array}{c}\text { Number of } \\
\text { voxels }\end{array}$} & \multirow{2}{*}{$\frac{\text { peak }}{\mathrm{T}}$} \\
\hline & & $\mathrm{x}$ & $\mathrm{y}$ & $\mathrm{z}$ & & \\
\hline \multirow[t]{2}{*}{$\mathrm{R}$} & Fusiform Gyrus & 32 & -46 & -22 & 173 & 7.195 \\
\hline & & 28 & -54 & -20 & & 3.681 \\
\hline \multirow[t]{2}{*}{$\mathrm{R}$} & Middle Occipital Gyrus & 30 & -82 & 18 & 261 & 6.001 \\
\hline & & 24 & -78 & 28 & & 4.401 \\
\hline $\mathrm{L}$ & Inferior frontal gyrus & -48 & 14 & 30 & 105 & 5.231 \\
\hline \multirow[t]{3}{*}{$\mathrm{L}$} & Fusiform Gyrus & -32 & -72 & -22 & 435 & 5.120 \\
\hline & & -30 & -68 & -14 & & 4.415 \\
\hline & & -14 & -86 & -8 & & 4.381 \\
\hline \multirow[t]{3}{*}{$\mathrm{R}$} & Angular Gyrus & 34 & -68 & 46 & 275 & 4.631 \\
\hline & & 26 & -74 & 48 & & 4.337 \\
\hline & & 36 & -56 & 42 & & 4.310 \\
\hline $\mathrm{L}$ & Fusiform Gyrus & -30 & -82 & 20 & 128 & 4.450 \\
\hline
\end{tabular}

Interpersonal_(social-individual) in Figure 10

\begin{tabular}{|c|c|c|c|c|c|c|}
\hline & \multicolumn{4}{|c|}{ Coordinates for max.voxel } & \multirow{2}{*}{$\begin{array}{c}\text { Number of } \\
\text { voxels }\end{array}$} & \multirow{2}{*}{$\begin{array}{c}\text { peak } \\
\mathrm{T}\end{array}$} \\
\hline & & $\mathrm{x}$ & $\mathrm{y}$ & $\mathrm{z}$ & & \\
\hline \multirow[t]{3}{*}{$\mathrm{R}$} & Lingual Gyrus & 6 & -70 & 0 & 706 & 6.636 \\
\hline & & 2 & -60 & 8 & & 4.338 \\
\hline & & 12 & -82 & 8 & & 4.329 \\
\hline \multirow[t]{3}{*}{$\mathrm{L}$} & Angular Gyrus or Inferior Parietal Lobule & -50 & -70 & 40 & 597 & 6.471 \\
\hline & & -52 & -52 & 34 & & 5.421 \\
\hline & & -60 & -62 & 28 & & 5.381 \\
\hline $\mathrm{L}$ & Middle Temporal Gyrus & -54 & -68 & 6 & 165 & 5.787 \\
\hline \multirow[t]{2}{*}{$\mathrm{L}$} & Precuneus & -6 & -58 & 40 & 245 & 5.274 \\
\hline & & -8 & -48 & 32 & & 4.823 \\
\hline $\mathrm{R}$ & Middle Temporal Gyrus & 50 & -62 & 2 & 135 & 4.779 \\
\hline
\end{tabular}

The left half of figure 9 shows the response within the brain when individuals carry out discounting behavior on their own. The upper left (2nd quadrant) shows the significant activated areas (biMT $(12,-86,40),(-6,-92,24))$ in the brain response in the case of an individual carrying out time discounting and interpersonal discounting, by subtracting the brain response to interpersonal discounting from the response to time discounting. The lower left (3rd quadrant) shows that, in the case of an individual carrying out time discounting and interpersonal discounting, although we looked for brain response by subtracting the brain response to time discounting from the response to interpersonal discounting, but there were no significant areas activated of either discounting. When subjects estimated their own time discount rate and interpersonal discount rate, the only activation recorded was in the visual cortex (biMT $(12,-86,40),(-6,-92,24))$ and there was no activation in the segment of the brain related to awareness of society. The right side of figure 9 indicates the brain response when the test subject is estimating not their own time/interpersonal discount rates but those of third parties (a society or group to which the person does not belong). In the top right (1st quadrant), we subtracted the brain response when the subject was estimating a third 
party's social discount from the response when estimating a third party's time discount and looked for any significant areas of activation, but we found no significant areas. The bottom right (4th quadrant) shows the brain activation area by subtracting the brain response when the subject was estimating a third party's time discount from the response when estimating a third party's social discount, and so we see that there were significant areas remaining (Intraparietal sulcas, Angular gyrus, biIPL $\left.(32,-60,46),(32,-42,44),(44,-56,50)^{8}\right)$.

In figure 10, the top half looks at the case of time discounting. The upper left side shows the response in the brain when estimating the time discount rate, and it shows the significant areas of activation (IFG $(-48,14,30)$, biMT $(12,-86,40),(-6,-92,24), \quad$ Fusiform $(32,-46,-22)$, rSPL $(-16,-56,70))$ that remain when the brain response while estimating the discount rate for a third party is subtracted from the brain response when discounting the subject's own discount rate. Conversely, the upper right shows that for time discounting, when the brain response occurring when the subject estimated his own discount rate is subtracted from the brain response when estimating the discount rate for a third party, no significant areas of activation were seen. The lower half of figure 10 is the case of social discounting and the lower left section shows that we looked for but did not find any significant areas of brain activation remaining after the brain response seen when the subject was estimating the social discount rate for a third party was subtracted from the brain reaction while the subject estimated their own social discount rate. The lower right section shows the significant areas of activation (ISMG (-60, -22,40), biMT (12, $-86,40),(-6,-92,24)$, the precuneus $(-6,-58,40))$ that resulted when the brain response occurring when the subject estimated their own social discount rate was subtracted from the brain response seen when the subject estimated the social discount rate for a third party.

In time discounting, the brain activation when determining one's own discount rate and that when determining the discount rate of a third party were similar, and even when social conditions were added, we saw no additional brain activity. That means that in time discounting, when determining the discount rate for oneself, that decision already reflects a certain sociality. Also, in terms of when the individual estimated their own interpersonal discount rate as well, it was assumed that brain activity would be similar to their own time discount, and no additional brain activity was seen. On the other

8 The inferior parietal lobule (biIPL) is involved in the perception of emotions in facial stimuli, and interpretation of sensory information. The biIPL is concerned with language, mathematical operations, and body image, particularly the supramarginal gyrus and the angular gyrus. Intraparietal sulcus is thought to play a role in some functions, including processing symbolic numerical information, visuospatial working memory and interpreting the intent of others. It is suggested that it plays a role in many consciousness-related functions, such as first-person perspective taking and the sense of agency. Also, it is suggested that it plays a significant role in self-awareness, with support from studies on loss of consciousness (and self-awareness). hand, in social discounting, when estimating the discounting rate of a third party, in comparison to the social conditions in time discounting and interpersonal discounting, we found activation in additional regions of the brain (the precuneus、IPL, TPJ, etc.). It can be said that the areas of the brain that recognize other people and society became increasingly activated. In other words, if we compare the findings of the existing analyses presented in section 2 with the results of our experiment, in both time discounting and interpersonal discounting, we found that the region of the brain that regulates the size of the discount and the region of the brain that gives meaning to the discount work together to carry out that discount. But based on our research results, time discounting behavior itself is the basis of discounting, and already mobilizes many of the portions of the brain that import meaning, so even in the case of interpersonal discounting, in the individual discount, we were unable to observe the activation of any new portions of the brain. In other words, it can be thought that the addition of social conditions in time discounting or interpersonal discounting, where to some degree sociality is added from the start, essentially divert the individual's processing system within the brain for time discounting, but in the case where social conditions are added in social discounting, new processing sections of the brain that strengthen self-awareness and awareness of others are being recruited. In addition, we were unable to specify brain areas that worked together to determine the size of the discount.

\section{Conclusions}

Based on the findings described in the previous sections, we can reach the following conclusion. The findings of the behavioral experiment revealed that in the cases of both time and interpersonal discounting, an individual's estimates of the discount rates of others are statistically significantly larger than their own discount rate. In terms of the system within the brain that regulates those types of discounts, time discounting is the basis, and up until the point of the individual's interpersonal discounting, that basic system is diverted to make those estimates, but when the sociality of others is added into the estimates of discount rates, it was found that new areas of the brain are recruited and new systems within the brain were being constructed.

We believe that these findings offer a basis to show the validity of the hypothesis that, with the increasingly fierce competition brought about by today's globalization of corporate management, which requires that decision-making take into consideration the reactions of more different types of people, people will intensify their own discount rate as a form of self-defense. In terms of time discounting, from the point where one is estimating 
one's own discount rate, the regions of the brain that control awareness of others were already activated, but in social discounting, the precuneus was activated, which reflects the promotion of the act of imagining the other person's social environment.

Therefore, based on the analysis in this paper, the intensification of two major management issues in recent years, short-termism and excessive executive compensation, can be explained by the intensification and repetition of the discounting behavior of managers as a result of economic globalization.

Management issues such as short-termism and excessive executive compensation are more accentuated by stimuli such as globalization. Such accentuation is caused by recruitment of new brain parts. This is a human instinctive behavior. If human instinctive reactions are harmful in terms of economic and normal rationality, accounting and economic policies will be needed to eliminate instinctive results (Armstrong et al.[1]).

But our brain experiment of discounting behavior is only personal experiment of dozens scale. Needless to say, additional experiments are required to use the results as a basis for trends in society as a whole.

\section{REFERENCES}

[1] Armstrong, C. S., Guay, W. R., \& Weber, J. P. (2010), " The Role of Information and Financial Reporting in Corporate Governance and Debt Contracting," Journal of Accounting and Economics, 50 (2-3), pp.179-234.

[2] Dallas, Lynne L. (2012), "Short-Termism, the Financial Crisis and Corporate Governance," Journal of Corporation Law 37, pp.315-316.

[3] Dutta, S. and S. Reichelstein (2003), "Leading indicator variable, performance measurement, and long-term versus short-term contracts," Journal of Accounting Research 41, pp.837-866.

[4] Dutta, S. and S. Reichelstein (2005), "Stock price, earnings, and book value in managerial performance measures," The Accounting Review 80, pp.1069-1100.

[5] Dutta, S. and X. Zhang (2002), "Revenue recognition in a multiperiod agency setting," Journal of Accounting Research 40, pp.67-83.

[6] Frederick, S., "Cognitive Reflection and Decision Making, (2005), " Journal of Economic Perspectives, Volume 19, Number 4, Fall 2005, pp.25-42.

[7] Harris, M. and A. Raviv(2008), "A thory of board control and size," Review of Financial Studies 21, pp.1797-1832.

[8] Ito M., and D. Saeki, (2000), "Discounting shared reward and selfishness", Paper presented at the 27th International Congress of Psychology, Stockholm., Sweden.

[9] Ito M., D. Saeki and L. Green, (2011), "Sharing, discounting, and selfishness: A Japanese-American comparison," The Psychological Record, 60, pp.59-76.

[10] Jones., B., and H. Rachlin, (2006), "Social Discounting," Psychological Science, Vol.17, No.4, pp.283-286.

[11] Kable, J. W., and P. W. Glimcher, (2007), "The neural correlates of subjective value during intertemporal choice," Nature Neuroscience, Vol.10, No.12, December, pp.1625-1633.

[12] Keynes, J.M., (1936), The general theory of employment, investment, and money, Chapter 12, 1936.

[13] Kubo, K., Lieberman, Matthew D., (2007), "Social Cognitive Neuroscience: A Review of Core Processes," The Annual Review of Psychology, 2007, 58:259-89.

[14] Marco-Pallares, J., B. Mohammadi, A. Samii and T. F. Munte, (2010), "Brain activations reflect individual discount rates in intertemporal choice," Brain Research, 1320, pp.12-129.

[15] McClure, S. M., et al., (2004), "Separate Neural Systems Value Immediate and Delayed Monetary Rewards," Science 306, 503, pp.503-507.

[16] Ostaszewski, P. and J. T. Osinski, (2011), "Social Discounting of Monetary Rewards - The Effects of Amount and Social Relationship-," European Psychologist, Vol.16 (3), pp.220-226.

[17] Parkinson, C., S. Liu and T. Wheatley, (2014), "A Common Cortical Metric for Spatial, Temporal, and Social Distance," The Journal of Neuroscience, January 29, 2014, 34(5), pp.1979-1987.

[18] Peters, J., and C. Buchel, (2009), "Overlapping and Distinct Neural Systems Code for Subjective Value during Intertemporal and Risky Decision Making," Journal of Neuroscience, December, 16, 29 (50), pp.15727-15734.

[19] Porter, M., (1992), "Capital disadvantage: America's failing capital investment system", Harvard Business Review [1 Septemeber 1992, 70(5):65-82]

[20] Rachlin, H., and B. Jones, (2007), "Social Discounting and Delay Discounting," Journal of Behavioral Decision Making, 20: pp.1-15.

[21] Raheja, C. (2005), "Determinants of board size and composition: a theory of corporate bosrds," Journal of Financial and Quantitative Analysis 40, pp.283-306.

[22] Takahashi, T., (2010). "A Social discounting model based on Tsallis' statistics," Physica A, 389, pp.3600-3603.

[23] Takahashi, T., (2013). "The q-Exponential Social Discounting Functions of Gain and Loss," Applied Mathematics, 2013, 4, pp.445-448.

[24] Yamakawa, Y., R. Kanai, M. Matsumura and E. Naito, (2009). "Social Distance Evaluation in Human Parietal Cortex," Plos One, February, Vol.4, Issue 2, e4360. 